Cahiers de recherches médiévales

La Figure de Jules César au Moyen Âge et à la Renaissance (II)

\title{
Le texte médiéval entre document et monument
}

Regards d'historiens, regards de littéraires

\section{Michèle Gally}

\section{(2) OpenEdition \\ Journals}

Édition électronique

URL : https://journals.openedition.org/crm/2580

DOI : $10.4000 / \mathrm{crm} .2580$

ISSN : $1955-2424$

Éditeur

Honoré Champion

Édition imprimée

Date de publication : 30 juin 2007

Pagination : 243-244

ISSN : $1272-9752$

Référence électronique

Michèle Gally, « Le texte médiéval entre document et monument », Cahiers de recherches médiévales [En ligne], 14 spécial | 2007, mis en ligne le 30 juin 2010, consulté le 15 décembre 2022. URL : http:// journals.openedition.org/crm/2580; DOI : https://doi.org/10.4000/crm.2580 


\section{RM}

\section{Le texte médiéval entre document et monument Regards d'historiens, regards de littéraires}

$\mathrm{Au}$ commencement un objet commun, le texte au creux du manuscrit. En sommeil. Réveillé par deux regards, deux discours possibles, celui de l'historien, celui du littéraire. L'opposition n'est pas toujours aussi nette et se mue en complémentarité souvent. C'est ce que ce dossier voudrait démontrer'. Lorsqu'il s'agit d'une production aussi lointaine et étrange que le texte médiéval, les deux fils, «littéraire » et "historique », s'entremêlent nécessairement pour nous permettre de l'ouvrir à une réception, de (re)construire une signification hésitante, hypothétique.

Demeurent certes des différences dans l'intention critique, la méthode, la transformation de ce texte muet en texte qui fait sens. De quel sens en effet s'agitil ? Car le texte, quand il peut être qualifié de «poétique», c'est-à-dire ordonné en vue d'une émotion, d'une qualité esthétique particulière, est éventuellement à la fois le miroir - document - et l'interprétation, projetée sur la scène de l'imaginaire, d'une société. Mais en cela il est aussi universel et hors de l'histoire, au-delà d'une société, d'une culture : «monument» qu'on peut encore lire pour lui-même ou qui participe à cette histoire particulière, entre réception et recréation, qu'est l'histoire des formes littéraires. Reprenons P. Zumthor qui a tant réfléchi sur ces distinctions : «Le texte est un événement, une information nouvelle surgissant du croisement de plusieurs lignes de réalité qui, en lui, s'abolissent comme telles; mais elles y engendrent une connotation globale qui reproduit le rapport vécu des hommes au monde et à eux-mêmes. [...] Le texte lit une histoire en s'insérant en elle, recoupe en les assimilant d'innombrables énoncés auxquels l'attache la communauté de langage $»^{2}$. Aussi la question posée au texte sera-t-elle différente si elle émane d'un littéraire ou d'un historien: "Qu'est-ce qui fait d'un message verbal une œuvre d'art?» demande Jakobson et non pas «Que nous apprend-il sur la société qui le produit?».

Les littéraires et les historiens médiévistes, cependant, ont une longue pratique de travail en commun, sans doute parce que leur objet passe en grande partie par les mêmes traces textuelles. Les uns et les autres, au cœur d'une expérience interprétative difficile et toujours de quelque manière audacieuse, réfléchissent ainsi à travers le dialogue qui se noue entre eux sur leurs sujets respectifs, la fiction pour les uns, la vérité historique pour les autres. Les deux en effet dépendent grandement de notre inscription dans une épistémè moderne étrangère à celle des textes que nous prétendons interpréter. «Un double défi est

\footnotetext{
${ }^{1}$ Les contributions publiées ici rassemblent une partie des interventions prononcées lors d'une journée d'études organisée à l'ENS Lettres et Sciences Humaines le 17 janvier 2005 par Michèle Gally et Bénédicte Milland-Bove. Que Nicole Bériou et John Baldwin, qui n’ont pas souhaité publier leurs interventions sur «Le sermon thématique, une construction fonctionnelle et esthétique » et «Jean Renart, Gerbert de Montreuil et l'histoire», soient ici remerciés pour leur précieuse participation.

${ }^{2}$ Essai de poétique médiévale, Seuil, 1972, p. 26.
}

Cahiers de Recherches Médiévales (XII -XV s.), 14spé, 2007 
lancé à l'historien sommé de répondre à deux questions essentielles à son métier : quelle est la nature de son objet, la «réalité » du document et de son référent ? [...] La question du rapport entre histoire et fiction se pose dans deux contextes différents : celui de l'histoire aujourd'hui et du rapport des historiens à la «vérité »; celui de la culture médiévale et de sa conception de la fiction ${ }^{3} »$.

Le «texte-témoin» médiéval a alors vocation à introduire chez tous ses savants lecteurs des interrogations épistémologiques et à remettre en cause les évidences. Ce peut être là aussi son intérêt et sa richesse.

Michèle Gally ENS Lettres et Sciences Humaines

${ }^{3}$ J.C. Schmitt, La Conversion d'Hermann le Juif, Seuil, 2003, p. 44. 